\title{
5. The TLL and the Sustaining of Scholarship
}

\section{ANTHONY CORBEILL}

University of Kansas

THE TLL HAS THE CAPACITY TO SUSTAIN AND NOURISH CLASSICAL SCHOLARSHIP well beyond the traditional confines of philology. This may sound surprising. After all, why should ancient historians and cultural critics consult a dictionary when they have access to resources such as Pauly-Wissowa or the Reallexikon für Antike und Christentum? Peter Burke, a cultural historian of early modern Europe, provides a way toward a response. Aware of the potential for work in his field to devolve into trendy observations and catchy anecdotes, he warns that cultural history approaches "the very real danger of trivialization whenever one of [its] topics is pursued for its own sake without any attempt to connect it with the surrounding culture" (Burke 1997: 61). For Latinists of the twenty-first century, the Thesaurus Linguae Latinae provides a means of connecting with "the surrounding culture" in ways that can produce a successful and meaningful cultural history.

The essay of Burke's from which I have quoted treats gesture in early modern Italy. One interesting phenomenon that he cites is the wholesale borrowing of Spanish words by Italians to describe the most genteel examples of their own body language, since members of the Spanish court at this time were seen to embody a particularly desirable form of corporeal grace. Cultural assumptions can often be resurrected from linguistic evidence in this way, and of course such a methodology is not foreign to a classicist, having a history in Rome going back at least to Varro. And since, for scholars of antiquity, words often constitute the most abundant evidence available, a reliable lexicon constitutes a key scholarly resource. In the study of ancient gesture in particular, it is difficult enough to use textual descriptions and conventional visual representations to reconstruct how Romans moved their bodies; one verges on fancy when using the same evidence to explain what these movements mean. In such cases, lexical evidence provides essential data for discovering the often unexpressed assumptions that lie behind a speaker's 
use of language. To demonstrate this potential, I will consider the TLL entries for four common words, proceeding chronologically through the lexicon. Just as more recently written articles demonstrate increasing lexicographical sophistication, so too do they provide easier access to information of interest to the cultural historian. My chosen lemmata each involve some aspect of the body: the nouns facies ("physical appearance, face"), gestus ("gesture"), and os ("mouth"), and the adjective pravus ("crooked").

Oskar Hey's entry on facies appeared in 1912. In accordance with Thesaurus practice, a modern etymology in square brackets immediately follows the lemma's dictionary form. This derivation agrees with ancient versions in associating facies with the verb facere ( $a$ facere ductum esse videtur). Hey supplements this conclusion by citing all but one of the ancient etymologies found in Maltby's Lexicon of Ancient Latin Etymologies of 1991 (i.e., Isid. orig. 11.1.33: facies dicta de effigie). Occupying special prominence is Gellius's discussion of the etymology, and Hey's cross-reference points the reader to its full citation later in the article. In this passage Gellius indicates how facies originally corresponded not to what we think of in English as "face" but to the body's general physical appearance. The organization of the article proceeds to mirror this ancient conception: section IA1 is devoted to passages that illustrate the meaning posited by Gellius as original, namely facies used to describe the entire body (de toto corporis habitu); this contrasts with IA2, where the meaning "face" predominates (de anteriore capitis parte). In the introductory section of IA2, Hey notes that Horace provides the first certain appearance of the restricted meaning, but he also helpfully includes crossreferences to earlier attestations that may also refer specifically to the face, thereby providing a useful supplement to Gellius $(46,11-13$ : certo huius significationis exempla non ante $\mathrm{HOR}$; habes sub 1, quae possis huc trahere, velut $p$. 45, 20.23.33. 36. 39 al.). The utility of the article for examining this distinction ends here, however. Hey created few additional subgroupings within A1 and A2, with each section representing principally a chronological arrangement of the archival database (on this point, see Flury, 1995: esp. 30-32).

In an article composed two decades later, there reappears the notion that a Roman could read in physical appearance a direct indication of a person's actions. For the lemma gestus, from 1930, Ida Kapp and Gustav Meyer spend considerably more time than Hey in distinguishing shades of meaning. Here again the introductory paragraph shows modern scholars concurring with ancient assessments that the noun derives from the verb gerere (Paul. Fest. p. 94: gestus quo indicatur, quid geratur). A gestus, in other words, was understood to refer to how one "carries" (gerere) oneself. The remainder of the article, again without explicit reference, demonstrates this claim, showing that a 
gesture in Roman culture is never an empty signifier but conveys, deliberately or not, information about its bearer. For example, the first occurrence of the word, and therefore by Thesaurus practice the first citation given in the main body of the article, effectively establishes this notion (Ter. Phorm. 890): "Now I must adopt a new gesture (gestus) and facial expression (vultus)." In this description of a dissimulating character, Terence explicitly joins gestus with vultus - the term describing the facial expression of internal desire - and Kapp and Meyer accordingly follow the citation with parallels for this collocation in later literature. Such a presentation allows the user to see at a glance the significance that gestus has, like vultus, in reading intention.

My next example concerns Roman mouths. The article os, oris has particular resonance for me since this word gave me something to talk about during the interview that led to my Thesaurus Fellowship. As a result of this salutary experience with the lemma, I viewed it as an etymological omen to learn upon my arrival in Munich in 1990 that Peter Flury, then Editor-in-Chief, was fond of asserting that "der Thesaurus ist kein Orakel" ("the Thesaurus is not an oracle"). By this proclamation Dr. Flury meant that no single entry in the lexicon is to be taken as objective and infallible; rather, as with any work of scholarship, each article is the product of human subjectivity, regardless of the care that goes into selecting examples and devising the framework within which they are laid. My own experience, however, leads me to invert Dr. Flury's assertion. The TLL is in fact oracular in the most literal sense: it offers data in cryptic language but, with time and study, that language can reveal some version of "truth." In another analogy with the oracle, each entry in recent fascicles strives to limit authorial intrusion, a principle reflected in print by the avoidance of the italic font that signal an author's presence. This last feature, the reining in of explicit interpretation, allows each entry to represent as directly as possible, through the words of the Romans, a lemma's semantic range. Here the resemblance to an oracle becomes most clear. As with the visitor to Delphi, for the TLL reader the task is to use ancient pronouncements to decode what words "mean."

My first exposure to the lexicon came while writing my dissertation. In an effort to understand Cicero's references to the mouths of political opponents, I pulled from the shelf volume IX, part 2. Fortunately, this turned out to be a relatively recent volume, with the fascicle containing os first published in 1980. Although allegedly a Latinist, I had had no prior introduction to the work, but since I was a doctoral candidate with a deadline, I was interested more in pillaging tendentiously than in understanding thoroughly. As I gazed perplexedly at nineteen pages of tightly-spaced Latin, where about every fifth word was an unfamiliar abbreviation, I was blessed by fortune. The editors 
had decided in this case to include an outline of the article, which allowed my first entry into this formidable work (note: with the electronic edition a mouse click can now access the outline of any article). Since I was particularly interested in how Cicero's description of certain oral activities—drinking, eating, oral sex-allowed him to use the mouth to draw negative conclusions about an opponent's entire physique, I immediately noted the section designated as CAPVT PRIMVM IB: the ways in which the os of a human being could refer by synecdoche to a person's head or body. The article's author, Renate Teßmer, had included in this section passages in which the os fills with tears (1082.69-1083.5 passim), or in which turning the head is described as turning the os (1086.48-57). This section provided preliminary lexical support for my claim that the Roman mouth possessed unique significance in ascertaining the characteristics of a face and that, in the hands of a capable orator, the mouth can dominate and define its bearer (Corbeill 1996:101-4).

This discovery led me to another section of the article, one that demonstrates how a TLL entry can provide significant information about syntactic matters as well as semantic. After providing a full selection of passages that describe the human mouth proper, Teßmer compiled an enormous collection of syntactical or grammatical structures (iuncturae selectae; 1075.59-1077.77): this appendix includes, for example, twenty-seven lines on the use of $o$ as an ablative of instrument ("licking up cakes with the os;" 1076.22-49) or eight lines on some of the different verbs for kissing that take os as direct object (1075.68-76). I was drawn in particular to the subsection entitled epitheta notabiliora, a list of the word's noteworthy epithets. Teßmer includes here adjectives modifying os to refer to bad character (ad mores malos pertinentia; 1077.43-50), with a helpful cross-reference to a fuller discussion of the os used sensu obsceno. At this moment TLL became a point of departure. Consultation of the non-Ciceronian passages at the cross-reference eventually led me to Richlin's Garden of Priapus (1992), where I learned that the bad character and "obscene use" consistently referred to the mouth's role in oral sex (a fact on which Teßmer maintained discreet silence while simultaneously providing all the most salient references). Using the PHI disk and Merguet's lexica to Cicero I then examined closely every Ciceronian use of the word os. Sensitized by Teßmer's list of epitheta notabiliora, I noticed that the addition of some kind of adjective to the word created special emphasis when Cicero referred to an opponent. "Qualifying the os," I concluded, "brings it to the audience's attention and activates it as an agent of immoral action" (Corbeill 1996, 103). I could not have reached this conclusion without the impetus and direction provided by the TLL. 
My final example involves an article that I wrote while a Fellow. In light of my interest in bodies and morality, I was fortunate to be assigned the adjective pravus ("crooked", both literally and morally). The material readily fell into two basic categories: conceptual crookedness (I potius spectat ad ea, quae animo percipiuntur) and literal crookedness (II potius spectat ad ea, quae sensibus percipiuntur). The Latin rubrics make clear that both meanings could coexist in one word, thereby providing further evidence for the extent to which Latin terms are embedded in a tangible perception of the world. The visibly crooked often equates with deviation from a moral norm; compare rectus ("upright") or aequus ("level"). Even among the far more numerous instances in which the adjective pravus describes moral deviance, there often lingers a concrete notion of "not straight-ness." Concise references in the article cue the user to this slippage without evaluating what it may mean (e.g., 1138.74-75: saepius sublucet usus sub II illustratus, e.g. p. 1139,30 ). I have returned repeatedly in my own scholarship to this notion of an interconnectedness between the physical world and the Roman moral universe, so that I take Nigidius Figulus's claim that Latin words arose "by a kind of force and reason within nature" (Gell. 10.4.1) as representative of the way Romans created, used, and interpreted vocabulary.

To cite the title of the volume celebrating the centennial of the Thesaurus, words grow out of Roman nature "like the leaves on a tree" ("wie die Blätter am Baum"). Accordingly, the TLL strives to represent a word's growth as an organic process whose changes can be re-traced meaningfully. The lexicon, by describing rather than defining words, orders for the reader the raw material from which to examine the ways in which a word's development has been determined by the systemic pressure of Roman culture. Opening the Thesaurus Linguae Latinae reveals not a series of prescriptions, but a wide-open book.

\section{WORKS CITED}

Burke, P. 1997. Varieties of Cultural History. Ithaca: Cornell University Press.

Corbeill, A. 1996. Controlling Laughter. Political Humor in the Late Roman Republic.

Princeton: Princeton University Press.

Flury, P. 1995. “Vom Tintenfaß zum Computer.” In Krömer,1995. 29-56.

Krömer, D., ed. 1995. Wie die Blätter am Baum, so wechseln die Wörter: 100 Jahre Thesaurus linguae Latinae. Stuttgart and Leipzig: Teubner.

Maltby, R. 1991. A Lexicon of Ancient Latin Etymologies. Leeds: Francis Cairns.

Richlin, A. 1992. The Garden of Priapus: Sexuality and Aggression in Roman Humor. Rev. ed. New York: Oxford University Press. 